\title{
Directed forgetting in pigeons
}

\author{
WILLIAM S. MAKI and DONNA K. HEGVIK \\ North Dakota State University, Fargo, North Dakota 58105
}

\begin{abstract}
Pigeons performed a version of delayed matching-to-sample in which different postsample cues signaled different trial outcomes. Cues to remember ( $R$ cues) signaled the usual comparison stimuli. Cues to forget ( $\mathrm{F}$ cues) signaled either cancellation of comparison stimuli (comparisonomission) or presentation of a sample-independent discrimination (comparison-substitution). As assessed by occasional probe trials, $\mathrm{F}$ cues decreased matching accuracy during comparisonomission more than during comparison-substitution. The loss in accuracy of matching in F-cue probes was directly related to length of delays during comparison-omission but not during comparison-substitution. Because trials generally terminated in reward during comparisonsubstitution but not during comparison-omission, these findings were interpreted as suggesting the importance of end-of-trial reinforcement for the maintenance of short-term memory.
\end{abstract}

Keeping memory current, that is, "updating" of memory (Bjork, 1978), involves mnemonic processes that are relatively well researched with human subjects. For example, there is an extensive literature illustrating how instructions to remember or to forget can be used to control human memory (Bjork, 1972). Although such "directed forgetting" is amply documented in research with humans, it remains unclear whether other species exhibit the same sensitivity to control of memory processing (Spear, 1978). Nevertheless, with the recent surge of interest in behavioral investigations of animal memory, some researchers have incorporated notions similar to directed forgetting in their accounts of memory processes in animals. Honig (1978) proposed that pigeons transform the nominal to-be-remembered stimulus into a representation of the to-be-executed response and then maintain that representation in memory until the response is executed, at which time that representation is "terminated." Similarly, Olton (1978) argued that rats form a working memory for spatial locations that is maintained for as long as needed and then "reset." Both of these views seem to be instances of the more general proposition that certain environmental events (such as those occurring at the end of trials) exert stimulus control over animal memory processes. It follows that something like directed forgetting should be demonstrable in animals as well as in humans. The present study was an attempt to provide evidence for a form of directed forgetting in pigeons.

This research was supported by National Institute of Mental Health Grant R01 MH31432-01. Experiment 1 was summarized at the 1979 meeting of the Midwestern Psychological Association. We thank Deborah Olson and Susan Rego for assistance with Experiment 2. Donna Hegvik (Anundson) is now at Texas Iech University. Requests for reprints should be sent to W. S. Maki, Department of Psychology, North Dakota State Universily, Fargo, North Dakota 58105

\section{EXPERIMENT 1}

Studies of animal short-term memory (STM) frequently employ versions of the delayed matchingto-sample (DMTS) task, referred to as "symbolic" or "conditional" matching. In a typical delayed conditional matching trial, one of two conditional stimuli (a sample) occurs and then, after a delay, two other (comparison) stimuli are presented. The animal's choice of a particular comparison is correct (reinforced) contingent on the identity of the preceding sample. Because the sample is not present when the choice is made, choice accuracy is taken as a measure of sample retention. The processes underlying DMTS performances are not yet clearly defined, but one account claims that sample memories are actively maintained ("rehearsed") throughout the delay (e.g., Maki, Moe, \& Bierley, 1977). Rehearsal can be viewed as an example of the behavior Lawrence (1963) referred to as a "coding response." The hypothesized instrumental nature of the coding response suggests that it can be brought under stimulus control, a line of reasoning that also points to the potential susceptibility of rehearsal to stimulus control.

The method that was developed to achieve such control (i.e., directed forgetting) evolved from two earlier studies (Maki, 1979; Maki, Gillund, Hauge, \& Siders, 1977). Both used versions of the DMTS task with pigeons, and both shared a common methodological feature: Following certain samples, comparison stimuli were omitted and retention of those samples was tested infrequently in probe trials containing the usual comparison stimuli. Both of those studies yielded a common result: The comparison-omission procedure decreased matching accuracy. While methodologically useful, these studies cannot be accepted uncritically as providing the needed evidence for directed forgetting. In both studies, either the sample 
itself or presample events signaled how the trial would end (in the presence or absence of comparison stimuli). That opens the possibility that differences in performance were caused by variations in processing of the sample. This concern led to a second methodological refinement-namely, postsample cuing. When different cues that follow every sample signal whether the trial will or will not end with a retention test (comparison stimuli), comparable processing of all samples can safely be assumed. The resulting procedure is thus a simplified version of the "intraserial cuing" (Bjork, 1972) technique used with human subjects (e.g., Woodward, Bjork, \& Jongeward, 1973).

In the first part of this experiment, the amnesic effects of a postsample cue signaling comparisonomission were demonstrated. In the second part, a prediction of the rehearsal hypothesis was tested. If, in the absence of rehearsal, sample memories are lost, and if postsample cues modulate rehearsal, then the loss in DMTS accuracy following postsample cues to forget should be an increasing function of the delay between cue and comparisons (i.e., time spent in the absence of rehearsal).

\section{Method}

Subjects. Six adult pigeons were used (one White Carneaux, three White Kings, and two Silver Kings). All birds had extensive experience with the version of DMTS used in the present experiment (see Maki, 1979). The birds were maintained at at least $80 \%$ of their free-feeding weights on a diet of mixed grain obtained as reinforcers during daily experimental sessions; supplemental grain was provided in home cages when required after sessions. Birds were housed individually and allowed unlimited access to grit and water.

Apparatus. A three-key conditioning chamber was used (see Maki, 1979, for specifications). Briefly, the front panel of the chamber contained three pecking keys backed by in-line projectors. Each projector could illuminate the key with a white, red, or green disk, or a vertical or horizontal white line. A houselight was located above and a grain feeder located below the center key. When the feeder was activated, its aperture was illuminated. Other than for these stimuli, the chamber was normally dark. Lightproofing and attenuation of extraneous sounds were achieved by placing the chamber in a ventilated, lightproof shell. An Automated Data Systems 1800E/II computer scheduled stimulus presentations and reported data via an on-line printer.

Procedure. Because of their prior training, all birds were performing the following task at high levels of accuracy $\mathbf{( 8 7 . 5 \%}$ correct). Each trial began with the presentation of a white disk on the center key. A single peck on the key darkened it and produced one of two equally probable samples: 2 sec access to grain (food) or $2 \mathrm{sec}$ during which no stimuli were presented (no food). A delay that contained no stimuli then occurred. Different delay lengths had been evolved for different birds during the course of previous training; the delays averaged $12.3 \mathrm{sec}$ (range: $6-15 \mathrm{sec}$ ). At the end of the delay, the two side keys were illuminated with red and green disks (comparison stimuli). A peck on the red key was reinforced (with 2 sec access to grain) if the trial had begun with food; a peck on the green key was reinforced if the trial had begun with no food. Otherwise, (incorrect) responses resulted in $2 \mathrm{sec}$ of darkness. After an intertrial interval of $20 \mathrm{sec}$ (also spent in darkness), the next trial was begun. Within each session, each combination of sample and position of correct side key occurred equally frequently in a random sequence.
The birds were further prepared to serve in the present experiment by being adapted to brief periods of illumination of the houselight during delays (which was one of the cues to be used later). During this "baseline" phase, half of each day's trials contained a .5-sec houselight presented $1.5 \mathrm{sec}$ after the offset of the sample. The 64 trials of each session were organized into eight randomized blocks. Within each block, each trial was uniquely defined by a combination of sample (food or no food), position of correct choice (right or left key), and occurrence of the .5-sec delay-interval illumination (light or dark). After each bird's performance had returned to criterial levels $(87.5 \%$ ) for 3 consecutive days for each combination of sample and illumination, the next phase of the experiment was begun. An average of 27 days (range: 16-52) was spent on baseline training.

Part A. All birds were then exposed to the comparison-omission procedure for 34 days. In all respects not mentioned below, procedural detaits were the same as in baseline training. The birds were first assigned in equal numbers to two groups such that delays were approximately the same average lengths in the two groups. For Group Light, delays averaged 11 sec (range: 6-15) and for Group Dark, delays averaged $13.7 \mathrm{sec}$ (range: 12-15). The two groups differed with respect to the function of postsample stimuli (light or dark). For Group Light, comparison stimuli were omitted in those trials containing the houselight during the delay; for Group Dark, comparison stimuli were omitted in those trials in which the houselight was not presented. During those trials in which comparisons were omitted, delays and intertrial intervals occurred as usual and an extra $2 \mathrm{sec}$ was added to the delay to compensate for the reinforcement duration of normal trials. Thus, for Group Light, the cue to remember ( $R$ cue) was postsample darkness and the cue to forget ( $F$ cue) was the brief postsample houselight; for Group Dark, the cue functions were reversed. The structures of the various trials presented during the comparison-omission phase are depicted in the top half of Table 1.

Probe-trial testing was conducted during the last 20 days of comparison-omission. During the terminal (eighth) block of trials on every other day, commencing with Day 16, all trials contained comparison stimuli and reinforcement for correct choices. A total of $40 \mathrm{~F}$-cue and $40 \mathrm{R}$-cue probe trials were thus presented. These tests completed Part $\mathbf{A}$.

Part B. Part B commenced with an additional 40 days of comparison-omission training. (After Part A, one bird in Group Light had experienced another 16 days of training in which its delay was increased from 6 to $7 \mathrm{sec}$.) These 40 days were organized into 20 pairs of days. One of the days in each pair contained trials in which the delay was "short" (i.e., $3 \mathrm{sec}$ for all birds). The other day in each pair contained the "long" delays previously determined for each bird. During these $\mathbf{4 0}$ days, no probe trials were presented. Then followed an additional 24 days of comparisonomission in which every other day contained a last block of probe trials. Alternate pairs of days contained short and long delays. Thus, these tests yielded $48 \mathrm{~F}$-cue and $48 \mathrm{R}$-cue probes, half of each containing short delays and half containing long delays. Experiment 1 terminated with a return to 10 days of baseline conditions in which half of each day's trials contained the houselight cue but all trials contained comparison stimuli and reinforcement for correct choices. Only long delays occurred during this training.

\section{Results}

Mean percentages correct were calculated for each bird and subjected to arcsin transformations to insure homogeneity of variance. These data were then entered into mixed analyses of variance that included identity of the $F$ cue (dark or light) as the between-groups factor and, as appropriate, Delay (short vs. long) and Cue ( $R$ vs. F) as within-subjects factors. Prelimi- 
Table 1

Trial Structures During Comparison-Omission and Comparison-Substitution Procedures

\begin{tabular}{|c|c|c|c|c|}
\hline \multirow[b]{3}{*}{ Cue } & \multicolumn{4}{|c|}{ Comparison } \\
\hline & \multicolumn{2}{|c|}{ Omission Procedure } & \multicolumn{2}{|c|}{ Substitution Procedure } \\
\hline & Food Sample & No-Food Sample & Food Sample & No Food Sample \\
\hline $\begin{array}{l}\mathrm{R} \\
\mathrm{F}\end{array}$ & $\begin{array}{l}\mathrm{R}+\mathrm{G}-\text { or } \mathrm{G}-\mathrm{R}+ \\
\text { (omitted) }\end{array}$ & $\begin{array}{l}\mathrm{R}-\mathrm{G}+\text { or } \mathrm{G}+\mathrm{R}- \\
\text { (omitted) }\end{array}$ & $\begin{array}{l}\mathrm{R}+\mathrm{G}-\text { or } \mathrm{G}-\mathrm{R}+ \\
\mathrm{V}+\mathrm{H}-\text { or } \mathrm{H}-\mathrm{V}+\end{array}$ & $\begin{array}{l}\mathrm{R}-\mathrm{G}+\text { or } \mathrm{G}+\mathrm{R}- \\
\mathrm{V}+\mathrm{H}-\text { or } \mathrm{H}-\mathrm{V}+\end{array}$ \\
\hline
\end{tabular}

Note-Comparison stimuli were red $(R)$ and green $(G)$ side keys; substituted comparisons were vertical $(V)$ and horizontal $(H)$ lines. Correct comparisons are indicated by " + " and incorrect comparisons are indicated by "-.."

nary inspection of the data indicated that the cuing effects depended on type of sample. Statistical analyses were therefore performed separately for samples of food and no food.

Probe trials. The results of probe-trial testing in Part $\mathrm{A}$ are presented in Table 2. The most important aspect of these results was the decrease in matching accuracy in F-cue probe trials relative to that obtained in R-cue probe trials. Accuracy of matching-to-samples of no food was significantly reduced by the $F$ cue $[F(1,4)=30.96, p<.01]$; the same tendency was noted for samples of food, but the effect was smaller and not reliable $[F(1,4)=2.62]$. In these analyses, there were no significant effects involving the identity of the $F$ cue [largest other $F(1,4)=1.99$ ].

The results from probe-trial tests in Part $B$ are also presented in Table 2. As in Part A, presence of an $F$ cue decreased matching accuracy relative to that observed following $\mathbf{R}$ cues. The size of the effect, however, tended to be complexly dependent on identity of the F cue (Groups), delay, and sample. For samples of no food, the cuing effect was evident only for those birds for which the houselight served as the $F$ cue, and that was true regardless of the length of the delay. Overall, matching following $R$ cues was more accurate than matching following $F$ cues $[F(1,4)$ $=18.20, \mathrm{p}<.05]$, performance of the dark group was superior to that of the light group $[F(1,4)=9.52$, $\mathrm{p}<.05]$, and these two factors interactively affected performance $[F(1,4)=8.26, p<.05]$. Following $R$ cues, performance was uniformly accurate and independent of other variables (all Fs $<1$ ); in contrast, matching accuracy following the $F$ cue was much less when the $F$ cue was the houselight than when the $F$ cue was darkness $[F(1,4)=20.69, p<.05]$. That the expected time-dependence of cuing effects was not obtained was indicated by the absence of a Cuing by Delay interaction [largest other $F(1,4)=1.24$ ].

Matching-to-samples of food in Part B exhibited a different pattern of results. Matching following $F$ cues tended to be less accurate than following $R$ cues $[F(1,4)=17.93, p<.05]$, and matching accuracy tended to be worse at long delays $[F(1,4)=9.78$, $\mathrm{p}<.05$ ]. Although the pattern of results displayed for samples of food in Table 2 suggests a Cuing by Delay interaction, that effect was not significant $[F(1,4)=3.09]$. Nevertheless, it can be noted that the cuing effect was reliable at long delays $[F(1,4)=$ $10.04, p<.05]$ but not at short delays $[F(1,4)=$ 4.84]. In these analyses, matching was unaffected by whether the F cue was light or darkness as indicated by the absence of any other significant effects [largest other $F(1,4)=1.41]$.

Baseline performances. During the first 3 days of

Table 2

Mean Percentage Correct Matching During Comparison-Omission and Comparison-Substitution as a Function of Sample, Postsample Cue, and Delay

\begin{tabular}{|c|c|c|c|c|c|c|c|c|}
\hline \multirow[b]{3}{*}{ Group } & \multirow[b]{3}{*}{ Cue } & \multicolumn{7}{|c|}{ Delay } \\
\hline & & \multicolumn{3}{|c|}{ Omission (1) } & \multicolumn{2}{|c|}{ Omission (2) } & \multicolumn{2}{|c|}{ Substitution (2) } \\
\hline & & Long (A) & Short (B) & Long (B) & Short & Long & Short & Long \\
\hline & & \multicolumn{7}{|c|}{ No-Food Sample } \\
\hline Dark & $\begin{array}{l}\mathbf{R} \\
\mathbf{F}\end{array}$ & $\begin{array}{l}90.0 \\
75.0\end{array}$ & $\begin{array}{l}88.9 \\
91.7\end{array}$ & $\begin{array}{l}88.9 \\
88.9\end{array}$ & $\begin{array}{l}93.0 \\
95.9\end{array}$ & $\begin{array}{l}87.8 \\
85.4\end{array}$ & $\begin{array}{l}93.5 \\
95.8\end{array}$ & $\begin{array}{l}90.0 \\
95.8\end{array}$ \\
\hline Light & $\begin{array}{l}\mathbf{R} \\
\mathbf{F}\end{array}$ & $\begin{array}{l}93.3 \\
63.3\end{array}$ & $\begin{array}{l}94.5 \\
47.2\end{array}$ & $\begin{array}{l}91.7 \\
61.1\end{array}$ & $\begin{array}{l}90.1 \\
66.7\end{array}$ & $\begin{array}{l}86.2 \\
66.7\end{array}$ & $\begin{array}{l}94.1 \\
79.1\end{array}$ & $\begin{array}{l}90.1 \\
75.0\end{array}$ \\
\hline Dark & $\begin{array}{l}\mathbf{R} \\
\mathbf{F}\end{array}$ & $\begin{array}{l}88.3 \\
81.7\end{array}$ & $\begin{array}{l}91.7 \\
83.3\end{array}$ & $\begin{array}{l}80.6 \\
58.3\end{array}$ & $\begin{array}{c}\text { Tood San } \\
96.1 \\
85.4\end{array}$ & $\begin{array}{l}84.8 \\
27.1\end{array}$ & $\begin{array}{r}96.5 \\
100.0\end{array}$ & $\begin{array}{l}86.1 \\
81.2\end{array}$ \\
\hline Light & $\begin{array}{l}\mathbf{R} \\
\mathrm{F}\end{array}$ & $\begin{array}{l}93.3 \\
78.3 \\
\end{array}$ & $\begin{array}{l}97.2 \\
94.4\end{array}$ & $\begin{array}{l}88.9 \\
61.1\end{array}$ & $\begin{array}{l}97.2 \\
87.5\end{array}$ & $\begin{array}{l}89.1 \\
41.7\end{array}$ & $\begin{array}{l}97.4 \\
91.7\end{array}$ & $\begin{array}{l}86.5 \\
66.7\end{array}$ \\
\hline
\end{tabular}

Note-Data are provided separately for each experiment ( 1 and 2) and for each part (A and B) of Experiment 1 . 
baseline training (adaptation to the houselight), a delay-interval illumination effect was noted; that is, the houselight significantly reduced matching accuracy. The effect tended to be larger for samples of no food, but significant effects of lighting were noted for both samples of no food $[F(1,4)=24.07, p<.01]$ and food $[F(1,4)=11.26, p<.05]$. As a consequence of the lengthy adaptation to the houselight during baseline training, these effects disappeared; by the last 3 days prior to introduction of the comparisonomission procedure, performances were in excess of $90 \%$ correct.

During the return to baseline following omission training, delay-interval stimuli designated as $F$ cues tended to disrupt matching. Matching accuracies during the first 3 days of postomission baseline training are summarized in Table 3. For samples of no food, matching was worse following $F$ cues than following $R$ cues $[F(1,4)=16.38, p<.05]$; the tendency for that effect to be greater when the $F$ cue was the houselight was not significant $[F(1,4)=4.36]$. A cuing effect was also noted on the average for samples of food, but the effect was more variable among birds and hence not reliable $[F(1,4)=2.72]$.

\section{Discussion}

A method for establishing stimulus control over maintenance of STM was introduced in the present experiment. One postsample stimulus (F cue) signaled the absence of comparison stimuli (i.e., no retention test), while another postsample stimulus signaled that comparison stimuli would be forthcoming at the end of the delay. Speaking casually, the occurrence of the $F$ cue informed the bird that there was no need to maintain the sample memory established in that particular trial. When F cues were then followed by comparison stimuli, matching was disrupted in occasional probe trials administered during comparisonomission training and also during the first few days of baseline training, in which all trials ended in comparison stimuli regardless of cue.

Unfortunately, the tendency for the cuing effect to vary in complex ways as a function of other variables precludes a simple interpretation. During probe-trial testing in Part A, a significant cuing effect was noted only for samples of no food, and during probe-trial testing in Part B, the pattern was even more complicated. For samples of no food, matching accuracy was decreased by $F$ cues in Part B but only for the birds for which the $F$ cue was the houselight. Because the interference from the $F$ cue was noted at both short and long delays, it could be argued that the houselight was reacted to as a sample of food on some trials (with illumination as the source of similarity between $\mathrm{F}$ cue and grain-hopper activation). That analysis, however, cannot be applied to the cuing effects noted with samples of food. If similarity of sample and cue was the only critical variable, matching should not have been impaired when the houselight was the $\mathrm{F}$ cue. To the contrary, at long delays, the accuracy of matching-to-samples of food was reduced by $F$ cues, regardless of whether those cues were light or darkness.

While no single, simple explanation adequately copes with all the data presented here, it appears that at least part of the data can be explained by postulating effects of F cues on STM. One such hypothesis is that $\mathrm{F}$ cues cause a decrease in rehearsal that has been assumed to occur during delays. According to the rehearsal hypothesis, sample traces are lost as a function of time spent in the absence of rehearsal. If the $F$ cue acted to halt rehearsal, then time-dependent effects of $F$ cues should be expected; probing retention shortly after the $F$ cue should show relatively little forgetting compared with probing retention after a more lengthy cue-comparison delay. Unfortunately, the results of Part B were equivocal. Cuing effects did tend to be larger at long delays, but only for samples of food, and, even then, the expected Cuing by Delay interaction was not significant.

\section{EXPERIMENT 2}

This second experiment was conducted for two reasons. The first aim was to provide additional data on the predicted time course of cuing effects, a prediction left unresolved by Experiment 1 . The second aim was to determine the feature of the comparisonomission procedure responsible for the production of potent $F$ cues. The suspicion motivating Experiment 1 was that signals correlated with presence and absence of tests of retention would gain "instructional" control over maintenance of STM. Some of the data reported above are consistent with that hypothesis, but they are also amenable to a quite different explanation. Note that the comparisonomission procedure actually results in omission of three events after $F$ cues. In addition to the comparisons being cancelled, neither choice responses nor opportunities for reinforcement occurred either. Thus, for example, reinforcement-omission rather than comparison-omission could be responsible for production of $\mathrm{F}$ cues, a possibility consistent with data on ratio reinforcement of matching. When end-of-trial reinforcement is scheduled after a fixed number of correctly completed trials, less accuracy is obtained on trials immediately following reinforcement (Nevin, Cumming, \& Berryman, 1963), and stimuli associated with positions of trials in the ratio (i.e., number of trials remaining to reinforcement) gain control over matching accuracy (Mintz, Mourer, \& Weinberg, 1966).

In the present experiment, a comparison-substitution procedure was devised to determine whether omissions 
of choice responses and reinforcement opportunities were important features of the comparison-omission procedure. In comparison-substitution, a different set of stimuli were substituted for the comparison stimuli following $F$ cues. One of these substituted stimuli was defined as correct regardless of the identity of the preceding sample, and choice of that stimulus was always reinforced. Note, however, that the substituted discrimination could be performed without retention of the sample stimulus. Therefore, if postsample cues exert instructional control over rehearsal, both substitution and omission procedures should produce effective $F$ cues; but if reinforcement-omission is important, F-cue effects should not develop during comparison-substitution training.

\section{Method}

Six adult White King pigeons were used. All were housed and maintained as in Experiment 1. All birds had previously served in a discriminative learning experiment but were naive with respect to the DMTS task. The same equipment was used.

The birds were first trained on the basic task (matching-tosamples of food and no food) described in Experiment 1 but with no delay between sample offset and comparison onset. Training was completed when a bird had met the same criterion $(87.5 \%$ correct for 3 days) as in Experiment 1. Acquisition of DMTS was completed in an average of 8.5 days (range: $7-10$ ). The birds were then trained to tolerate progressively longer delays. During the 30 days of delay training, delays were increased $.5 \mathrm{sec}$ per day, contingent on criterial performance. Further delay training took an average of 12.7 additional days (range: 8-21) during which delays were adjusted downward as necessary to achieve consistent criterial performance. At the end of this training, delays averaged $7 \mathrm{sec}$ (range: 5-9). These delays were subsequently used as long delays. Delay training concluded with 10 days during which half of each day's trials contained short (2-sec) delays.

After the completion of delay training, each bird was prepared to serve in this experiment in the same manner as in Experiment 1. During this preparatory phase, the birds were adapted to brief $(.5-\mathrm{sec})$ flashes of the houselight, presented $1 \mathrm{sec}$ after the samples during half of the 32 short-delay and half of the 32 long-delay trials in each session. Adaptation training, which took an average of 29 days (range: 10-54) was completed for each bird when its performance had returned to critical levels.

During the next 30 days of comparison-substitution training, the postsample cues (light and dark) were correlated with different end-of-trial events. Trials containing $R$ cues terminated with the normal (red and green) comparison stimuli and reinforcement for correct choices. Trials containing $F$ cues, however, terminated with the presentation of two lines (vertical and horizontal) on the side keys. A single peck on the key containing the vertical line was always reinforced, regardless of position and independently of the identity of the preceding sample; a peck on the key containing the horizontal line also darkened the two side keys but was never reinforced. Thus, the presentations of vertical and horizontal lines constituted a simple discrimination task. For two of the birds, darkness served as the $R$ cue and the houselight served as the $F$ cue; for the remaining four birds, the cue functions were reversed. The various trial structures in this procedure are presented in Table 1 (in which they are contrasted with trial structures in the comparison-omission procedure).

During the next 24 days, two probe trials were added to each session, bringing the total number of trials/session to 66 . The probe trials were scheduled randomly to occupy one of the trial positions between 17 and 33 and between 50 and 66 . Within each randomized block of eight probe trials (spanning 4 days), trials were uniquely defined by a combination of delay, sample, and position of correct choice. All probes contained $F$ cues and terminated with the red and green comparison stimuli and reinforcement for correct (sample-dependent) choices. This testing procedure thus resulted in data from $24 \mathrm{~F}$-cue probe trials at each delay.

All birds were then returned to baseline (adaptation) conditions in which all trials ended in the usual comparison stimuli and reinforcement for correct responses regardless of lighting conditions during the delays. This training took an average of 11.7 days (range: 4-39) to insure stable, criterial performances. The birds were then exposed to 30 days of comparison-omission training conducted as in Experiment 1 except that short and long delays were intermixed within days. Cue functions remained as in the comparison-substitution phase. The experiment ended with 24 days of testing with F-cue probes as described above (but in the context of comparison-omission rather than comparison-substitution training), followed by 4-12 days of baseline training.

\section{Results}

As in Experiment 1, each bird's percentages correct were subjected to arcsin transformations, and separate analyses of variance were then performed on scores for matching-to-samples of food and no food.

Probe trials. Data obtained during the 24 days of probe-trial tests during both comparison-substitution and comparison-omission phases are summarized in Table 2. The table contains mean percentages correct for both F-cue (probe) and R-cue trials, which are displayed separately for different samples and different delays for the different groups. The F-cue means are based on 12 trials per bird and the R-cue means are based on 192 trials.

Consider, first, the data obtained with samples of no food. The birds for which the F cue was the houselight (Group Light) performed worse in probe trials than the birds for which the F cue was darkness (Group Dark) $[F(1,4)=41.61, p<.01]$. The difference was greater when probe trials contained $\mathrm{F}$ cues as indicated by the significant Cuing by Groups interaction $[F(1,4)$ $=10.18, p<.05]$. These effects did not vary as a function of Delay or Treatment (omission vs. substitution) [largest other $F(1,4)=2.22$ ]. Simple main effects analyses revealed that Groups Dark and Light did not differ on those trials containing $R$ cues [largest $F(1,4)=2.05]$, but Group Light performed worse than did Group Dark on probe trials containing $F$ cues $[F(1,4)=29.40, p<.01$; largest other $F(1,4)=1.70]$. Next, consider the data obtained with samples of food. Overall, matching following $F$ cues was less accurate than matching following $R$ cues $[F(1,4)=$ 83.05, $\mathrm{p}<.001$ ], and matching during comparisonomission tended to be worse than matching during comparison-substitution $[\mathrm{F}(1,4)=7.36, \mathrm{p}<.06]$. Those variables interactively affected performances such that the cuing effect was largest during comparison-omission $[\mathrm{F}(1,4)=7.71, \mathrm{p}<.05]$. Also, matching accuracy decreased as a function of cuecomparison delay $[F(1,4)=403.28, p<.001]$, and this decrease was greatest after $F$ cues, as indicated by the significant Cuing by Delay interaction $[F(1,4)=$ 
$106.89, \mathrm{p}<.001]$. No other main effect or interaction was significant [largest other $F(1,4)=2.33$ ].

To further explore the Cuing by Delay interaction, simple analyses of variance were conducted on data from matching-to-samples of food at each delay. As is apparent from the pattern of data in Table 2, matching following short cue-comparison delays was not greatly affected by any of the variables [cuing, treatments, or groups; largest $F(1,4)=2.39$ ]. In contrast, matching-to-samples of food following long delays was less accurate following $F$ cues $[F(1,4)=162.20$, $\mathrm{p}<.001]$ and was also less accurate during comparison-omission than during comparisonsubstitution $[F(1,4)=14.11, p<.05]$. Of special interest was the tendency for the cuing effect to be larger during comparison-omission than during comparison-substitution $[\mathrm{F}(1,4)=17.62, \mathrm{p}<.05$; largest other $F(1,4)=3.15]$. Simple main effects analyses showed that matching-to-samples of food following $R$ cues after long delays did not differ between comparison-omission and comparisonsubstitution treatments [all Fs $<1$ ); matching following $F$ cues after long delays, on the other hand, was much less accurate during comparison-omission than during comparison-substitution $[\mathrm{F}(1,4)=27.36, \mathrm{p}<.01]$, and this difference was independent of the identity of the $F$ cue [largest other $F(1,4)=4.37]$.

Baseline performances. During the first 3 days of exposure to baseline conditions (in which the brief houselight was introduced in half the trials), all birds' matching accuracies were reduced by the delay-interval illumination. Accuracy of matching-to-samples of no food was decreased by the presence of the houselight $[F(1,5)=67.55, p<.001]$ and at long delays $[F(1,5)$ $=7.31, \mathrm{p}<.05]$, but these factors did not interact $(F<1)$. In contrast, accuracy of matching-to-samples of food was jointly affected by Lighting and Delay $[F(1,5)=9.19, p<.05$; largest other $F(1,5)=2.38]$; as confirmed by simple main effects analyses, matching was significantly reduced by the houselight at short delays $[\mathrm{F}(1,5)=8.11, \mathrm{p}<.05]$ but not at long delays $(F<1)$. As in Experiment 1 , extended adaptation to the houselight during initial baseline training abolished these interference effects such that, by the last 3 days of baseline training prior to the introduction of the comparison-substitution procedure, performances were very accurate (exceeding $87.5 \%$ correct).

During the first 3 days of baseline training following comparison-substitution, it was apparent that the houselight was again disruptive; mean accuracies are presented in Table 3. For matching-to-samples of no food, however, the effect was not significant [largest $F(1,4)=3.73]$. The interference when the $F$ cue was the houselight was somewhat more pronounced for matching-to-samples of food, as suggested by the significant Cuing by Groups interaction $[F(1,4)=$ $38.98, \mathrm{p}<.01$ ]. Although matching-to-samples of food was generally worse following $F$ cues $[F(1,4)=$ 14.91, $\mathrm{p}<.05$ ] and tended to be worse following long delays $[F(1,4)=6.14, p<.07]$, these two factors did not interact [largest other $F(1,4)=3.33$ ]. After additional baseline training, these effects disappeared; performances averaged over $90 \%$ correct during the last 3 days prior to the comparison-omission procedure.

The effects of the comparison-omission procedure on matching during the return to baseline are also portrayed in Table 3 in terms of mean percentages correct during the first 3 days of postomission baseline training. For matching-to-samples of no food, the $F$ cue tended to be disruptive if it was the houselight, as was the case following comparison-substitution; the interaction of Cuing and Groups approached significance $[F(1,4)=7.14, p<.06$; largest other $F(1,4)=5.38$ ]. For matching-to-samples of food, however, the effects were quite different. Matching accuracy was poorer following $F$ cues $[F(1,4)=$ $15.18, \mathrm{p}<.05]$ and after long delays $[\mathrm{F}(1,4)=6.95$, $\mathrm{p}<.06]$. That the cuing effect was greatest at long delays was confirmed by the significant Cuing by

Table 3

Mean Percentage Correct Matching During Postomission and Postsubstitution Baseline Training

\begin{tabular}{|c|c|c|c|c|c|c|}
\hline \multirow[b]{3}{*}{ Group } & \multirow[b]{3}{*}{ Cue } & \multicolumn{5}{|c|}{ Delay } \\
\hline & & \multicolumn{3}{|c|}{ Omission } & \multicolumn{2}{|c|}{ Substitution } \\
\hline & & Long (1) & Short (2) & Long (2) & Short (2) & Long (2) \\
\hline & & \multicolumn{5}{|c|}{ No-Food Sample } \\
\hline Dark & $\begin{array}{l}\mathbf{R} \\
\mathrm{F}\end{array}$ & $\begin{array}{l}90.3 \\
85.4\end{array}$ & $\begin{array}{l}89.6 \\
96.9\end{array}$ & $\begin{array}{l}85.4 \\
94.8\end{array}$ & $\begin{array}{l}92.7 \\
95.8\end{array}$ & $\begin{array}{l}89.6 \\
90.6\end{array}$ \\
\hline \multirow[t]{2}{*}{ Light } & $\begin{array}{l}\mathbf{R} \\
\mathrm{F}\end{array}$ & $\begin{array}{l}90.3 \\
68.7\end{array}$ & $\begin{array}{l}87.5 \\
70.8\end{array}$ & $\begin{array}{l}89.6 \\
77.1\end{array}$ & $\begin{array}{l}95.9 \\
72.9\end{array}$ & $\begin{array}{l}91.7 \\
72.9\end{array}$ \\
\hline & & \multicolumn{5}{|c|}{ Food Sample } \\
\hline Dark & $\begin{array}{l}\mathrm{R} \\
\mathrm{F}\end{array}$ & $\begin{array}{l}81.9 \\
64.6\end{array}$ & $\begin{array}{l}93.8 \\
85.4\end{array}$ & $\begin{array}{l}91.7 \\
53.1\end{array}$ & $\begin{array}{l}94.8 \\
99.0\end{array}$ & $\begin{array}{l}85.4 \\
86.5\end{array}$ \\
\hline Light & $\begin{array}{l}\mathrm{R} \\
\mathrm{F}\end{array}$ & $\begin{array}{l}84.0 \\
61.8\end{array}$ & $\begin{array}{l}95.8 \\
93.8\end{array}$ & $\begin{array}{l}91.7 \\
45.9\end{array}$ & $\begin{array}{l}97.9 \\
70.8 \\
\end{array}$ & $\begin{array}{l}93.8 \\
77.1 \\
\end{array}$ \\
\hline
\end{tabular}

Note-Data are based on the first 3 days of postomission (Experiments 1 and 2) and postsubstitution (Experiment 2) baseline training. 
Delay interaction $[F(1,4)=33.76, p<.01]$. Simple main effects analyses showed that the small cuing effect at the short delay was not reliable [largest $F(1,4)=4.46]$ in contrast with the large cuing effect at the long delay $[\mathrm{F}(1,4)=20.69, \mathrm{p}<.05$; other Fs $<1$.

Analyses of replicated experiments. Inspection of Tables 2-3 reveals considerable similarity in results obtained from manipulations common to Experiments 1 and 2. Yet, comparison of the outcomes of statistical analyses associated with each experiment suggests a less orderly pattern, one that could be taken to imply a certain lack of replicability (e.g., the nonsignificant Cuing by Delay interaction for samples of food in Experiment 1). In order to determine how seriously such differences should be taken, additional analyses of variance were performed that included Replications (Experiment 1 vs. Experiment 2) as a factor (see Winer, 1962, pp. 213-216).

The analyses examined arcsin-transformed proportions of correct matching in probe trials during comparison-omission in Experiments 1 (Part B) and 2. The data included in this analysis are summarized in Table 2. Matching-to-samples of no food was less accurate in Group Light than in Group Dark $[\mathrm{F}(1,8)=$ 18.64, $\mathrm{p}<.01$ ] and less accurate following $F$ cues $[F(1,8)=10.89, p<.05]$. Following $R$ cues, matching was equally accurate in both groups [largest $F(1,8)=$ 2.36], but matching by birds in Group Dark was significantly better than that by birds in Group Light following $F$ cues $[F(1,8)=24.48, p<.01$; largest other $F(1,8)=1.70$ ]. That these effects were similar in both experiments is suggested by the lack of any other significant effect involving Replications [largest other $F(1,8)=3.54]$.

The results of the same analysis applied to accuracies of matching to samples of food yielded a different picture. Matching was less accurate after $F$ cues $[F(1,8)=43.64, p<.001]$ and at long delays $[F(1,8)$ $=37.78, \mathrm{p}<.001]$. Moreover, the Cuing by Delay interaction was also significant $[\mathrm{F}(1,8)=16.63, \mathrm{p}<$ $.01]$. At short delays, the relatively small cuing ef fect was not significant $[F(1,8)=4.27$; largest other $\mathrm{F}(1,8)=1.23$, while at long delays, matching after $F$ cues was much less accurate than after $R$ cues $[F(1,8)=51.76, p<.001$; largest other $F(1,8)=$ 4.24]. These statements apply equally well to both experiments and are independent of the identity of the cue because no effects involving Replications or Groups were reliable [largest $F(1,8)=2.61$ ]

\section{GENERAL DISCUSSION}

Taken together, the results of both experiments described above provide grounds for the following conclusions about directed forgetting in pigeons. First, postsample stimuli associated with the absence of end-of-trial events reduce matching accuracy. The effect is sufficiently robust so as to be observable under different testing conditions involving minor procedural changes. The effects of F cues on DMTS accuracy were observed when probe trials were distributed within sessions (Experiment 2) as well as when massed at the end of sessions (Experiment 1) and also when baseline training conditions were reinstated (both experiments). The procedural generality of the cuing effect is in fact even greater. Stonebraker, Kendrick, and Rilling (Note 1) have now reported replications and extensions of the present studies. In one of their experiments, a "successive matching" procedure was used, and $\mathrm{F}$ cues disrupted performance following comparison-omission training.

The second conclusion is that cuing effects can vary with the nature of the to-be-remembered sample. In both Experiments 1 and 2, accuracies of matchingto-samples of no food were disrupted by $F$ cues but only when the houselight served as the $F$ cue (see Table 2). One way to explain this effect is by noting that the original effect of delay-interval illumination on DMTS accuracy was also confined to matchingto-samples of no food. Even though considerable time was devoted to adapting the birds to the houselight, the interference from delay-interval illumination might therefore have recovered during the comparisonomission training. The same explanation does not apply to the effects of $F$ cues on matching-to-samples of food; both presence and absence of the houselight were equally effective in disrupting performance. Moreover, the fact that cuing effects depended on specific samples in this study does not mean that cuing effects are always sample dependent; Stonebraker et al. (Note 1) used visual samples (red and green keylights) and obtained cuing effects for both to-beremembered events.

The third conclusion is that the effects of an F cue on matching are time dependent. In both Experiments 1 and 2, matching-to-samples of food was worse at long than at short delays. This finding (now also replicated with visual samples by Stonebraker et al.) is consistent with the proposition that sample memories are rehearsed during the delay, that $\mathrm{F}$ cues terminate rehearsal, and that forgetting occurs as a function of time spent in the absence of rehearsal.

The fourth conclusion is that comparison-omission per se may not be responsible for the production of an $F$ cue. Instead, either the lack of an opportunity to choose among simultaneously presented stimuli or the lack of an opportunity for reinforcement seems to be critical. This conclusion is supported by the attenuation of the cuing effect (and its time dependence) by the comparison-substitution procedure in Experiment 2, and Stonebraker et al. (Note 1) report a nearly identical manipulation that eliminated cuing effects. It is thus clear that providing substitute discriminative stimuli and reinforcement for a correct choice at the end of the delay does not produce effective I cues, even though level of sample retention is irrelevant to performance of the substitute discrimination. 
The failure of the substitution procedure to produce the expected cuing effect is troublesome from the standpoint of a rehearsal hypothesis. Because the different effects of omission and substitution treatments do not follow from that hypothesis in any simple, direct way, possible alternative explanations should be entertained. For example, it may be that variations in delayed matching performances are due to variations in peripheral mechanisms. Stonebraker et al. noted that birds oriented away from the pecking keys following $F$ cues during comparison-omission but not during comparison-substitution. Thus, overt mediating behaviors maintained by end-of-trial reinforcement (and disrupted by $\mathrm{F}$ cues) might be necessary for accurate matching.

The differential effectiveness of the comparisonomission and comparison-substitution procedures, however, is not necessarily inimical to a rehearsal hypothesis. Even a central account, though, needs to acknowledge the importance of variations in trial outcomes following $\mathrm{F}$ cues. Only in the comparisonomission procedure were the $R$ and $F$ cues and the behaviors that followed them differentially reinforced. On this elaborated account, then, the act of maintaining the sample memory (rehearsal) would be extinguished following $\mathrm{F}$ cues only under conditions of differential reinforcement (i.e., comparison-omission). The present findings do not allow a firm decision between central and peripheral explanations, and we must therefore wait for further research to clarify the basis of what we have called directed forgetting in pigeons.

\section{REFERENCE NOTE}

1. Stonebraker, T. B., Kendrick, D. C., \& Rilling, M. Control of delayed matching-to-sample performance using directed forgetting techniques. Unpublished manuscript, 1980.

\section{REFERENCES}

BJoRk, R. A. Theoretical implications of directed forgetting. In A. W. Melton \& E. Martin (Eds.), Coding processes in human memory. Washington, D.C: Winston, 1972.

BJork, R. A. The updating of human memory. In G. H. Bower (Ed.), The psychology of learning and motivation: Advances in research and theory (Vol. 12). New York: Academic Press, 1978.

Honic, W. K. Studies of working memory in the pigeon. In S. H. Hulse, H. Fowler, \& W. K. Honig (Eds.), Cognitive processes in animal behavior. Hillsdale, N.J: Erlbaum, 1978.

LAWRENCE, D. H. The nature of a stimulus: Some relationships between learning and perception. In S. Koch (Ed.), Psychology: A study of a science (Vol. 5). New York: McGraw-Hill, 1963.

Макı, W. S. Pigeons' short-term memories for surprising vs. expected reinforcement and nonreinforcement. Animal Learning \& Behavior, 1979, 7, 31-37.

Maki, W. S., Gillund, G., Hauge, G., \& Siders, W. Matching to sample after extinction of observing responses. Journal of Experimental Psychology: Animal Behavior Processes, 1977 , 3, 285-296.

Mak1, W. S., Moe, J. C., \& Bierley, C. M. Short-term memory for stimuli, responses, and reinforcers. Journal of Experimental Psychology: Animal Behavior Processes, 1977, 3, 156-177.

Mintz, D. E., Mourer, D. J., \& Weinberg, L. S. Stimulus control in fixed ratio matching-to-sample. Journal of the Experimental Analysis of Behavior, 1966, 9, 627-630.

Nevin, J. A., Cumming, W. W., \& Berryman, R. Ratio reinforcement of matching behavior. Journal of the Experimental Analysis of Behavior, 1963, 6, 149-154.

OLton, D. S. Characteristics of spatial memory. In S. H. Hulse, H. Fowler, \& W. K. Honig (Eds.), Cognitive processes in animal behavior. Hillsdale, N.J: Erlbaum, 1978.

SPEAR, N. E. The processing of memories: Forgetting and retention. Hillsdale, N.J: Erlbaum, 1978.

Winer, B. J. Statistical principles in experimental design. New York: McGraw-Hill, 1962.

Woodward, A. E., Bjork, R. A., \& Jongeward, R. H. Recall and recognition as a function of primary rehearsal. Journal of Verbal Learning and Verbal Behavior, 1973, 12, 608-617.

(Received for publication February 22, 1980; revision accepted July 2, 1980.) 